\title{
Bitkisel ekstrakt karışımlarının broylerlerde performans, karkas randımanı ve bazı iç organ ağırlıkları üzerine etkisi ${ }^{* *}$
}

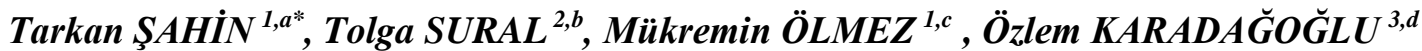 \\ ${ }^{1}$ Kafkas Üniversitesi Veteriner Fakültesi Hayvan Besleme ve Beslenme Hastalıklarl AD., Kars, Türkiye \\ ${ }^{2}$ Kafkas Üniversitesi Sağllk Bilimleri Enstitüsü,, Kars, Türkiye \\ ${ }^{3}$ Kafkas Üniversitesi Kars Meslek Yüksekokulu Bitkisel ve Hayvansal Üretim Bölümü., Kars, Türkiye \\ ORCID: 0000-0003-0155-2707 ${ }^{a}$;0000-0002-1272-6648 ${ }^{b}$;0000-0002-5003-3383 ${ }^{c}$;0000-0002-5917-9565
}

\author{
MAKALE BİLGISİ/ \\ ARTICLE \\ INFORMATION: \\ Geliş / Received: \\ 06 Şubat 20 \\ 06 February 20 \\ Kabul / Accepted: \\ 09 Mayis 20 \\ 09 May 20
}

Anahtar Sözcükler:

Bitkisel Ekstrakt

Broyler

Karkas randımanı

Performans

Keywords:

Broiler

Carcass Yield

Herbal Extract

Performance
ÖZET:

$\mathrm{Bu}$ araştırma broyler rasyonlarına farklı düzeylerde ilave edilen bitkisel ekstrakt karışımının (BEK) performans karkas parametreleri ve bazı iç organ ağırlıkları üzerine etkilerini belirlemek amacıyla gerçekleştirilmiştir. Çalışmada toplam 192 adet günlük yașta karıșık cinsiyette broyler civciv (Ross 308) her birinde 48 civciv bulunan dört gruba ayrılmıștır. Gruplar kendi içinde 12 adet hayvan içeren 4 alt gruba ayrılmıştır. Araştırmada bir kontrol ve üç deneme grubu oluşturulmuştur. Deneme gruplarının rasyonlarına sırası ile $1 \mathrm{gr} / \mathrm{kg}, 2 \mathrm{gr} / \mathrm{kg}$ ve $4 \mathrm{gr} / \mathrm{kg}$ düzeyinde BEK ilave edilmiştir. Deneme 42 gün sürdürülmüştür. Deneme sonunda rasyonlara ilave edilen BEK, performans parametreleri, kesim parametreleri ve iç organ ağırlıkları üzerine anlamlı bir farklılık oluşturmamıştır. Çalışmada BEK' in performans değerleri üzerine etki göstermemesi aktif moleküllerinden ve uygulama dozundan kaynaklandığı düsünülmektedir. Sonuç olarak bitkisel ekstrakt karıșımının performans değerleri, karkas ve iç organ ağırlıkları üzerine önemli değişikliklere neden olamadıkları, ancak adı geçen katkıların optimum karışımlarının dozları belirlenerek farklı dozlarda farklı dönemlerde hayvanlar üzerinde etkilerinin incelenmesinin faydalı olacağı kanaatine varılmıştır.

\section{Effects of herbal extract mixtures on performance, carcass yield and some internal organ weight in broilers}

\section{ABSTRACT:}

This study was realized to determine the effects of the mixture of herbal extracts added to broiler rations on performance carcass parameters and some internal organ weights. In this study, a total of 192 mixed-age broiler chicks (Ross 308) were divided into four groups, each with 48 chicks. The groups were divided into 4 subgroups, which included 12 animals. In the trial, groups were composed as control and three treatment groups. Basal diets were supplemented with herbal extract $\operatorname{mix}(\mathrm{HEM})$ at $1 \mathrm{~g} / \mathrm{kg}, 2 \mathrm{~g} / \mathrm{kg}$ and $4 \mathrm{~g} / \mathrm{kg}$ levels, respectively. The experiment was continued for 42 days. The end of the experiment, performance parameters of HEM added to rations did not create statistically significant differences on cutting parameters and internal organ weights. In the study, it is thought that the extract was no effect on performance values is due to active molecules of the extract and the level of application to animals in broiler rations. As a result, it was concluded that the herb extract could not cause significant changes on the growth performance, carcass and internal organ weights, but determined the doses of the optimum mixtures of these additives and it would be beneficial to research the effects of the animals on different doses at different periods.

How to cite this article: Şahin T, Sural T, Ölmez M, Karadağoğlu Ö: Bitkisel ekstrakt karışımlarının broylerlerde performans, karkas randımanı ve bazı iç organ ağırlıkları üzerine etkisi. Veteriner Hekimler Dernegi Dergisi, 91(2): 137-146, 2020, DOI: 10.33188/vetheder.685635 


\section{Giriş}

Etlik piliçlerin beslenmesinde amaç en kısa sürede en az yem tüketimi ile en yüksek canlı ağırlığa ulaşmaktır. $\mathrm{Bu}$ verime kısa sürede ulaşmak için broyler rasyonlarının hazırlanmasında rasyondaki besin maddelerinin dengeli tutulmasının yanında verim arttırıcı çeşitli yem katkı maddeleri kullanılmıştır. Bu amaçla antibiyotikler yaygın olarak kullanılmıştır $(1,2)$.

Kanatlı sektöründe antibiyotiklerin yasaklanmasıyla birlikte doğal büyütme faktörleri arayışı gündeme gelmiştir (3). Bitkisel ekstraktların en önemli etkileri patojen mikroorganizmaların çoğalmasını önlemek ve midebağırsak florasını dengede tutmaktır. Sindirim kanalı içindeki enzimlerin aktivitesi için pH'yı dengelemede bitkisel ekstraktlar önemli rol oynayarak bağırsaktaki dengeyi sağlarlar (4). Fitojenik ürünler terpenidler ve fenilpropan gibi iki ana keton bileşikten oluşurlar (5). Bu bileşikler anetol gibi birçok biyoaktif moleküle sahiptir. Anetol anasonun (Pimpinella anisum ), rezenenin (Foeniculum vulgare) ve diğer birçok bitkinin uçucu yağında bulunur. Bunlardan alisin, allil-izotiyosiyanatisineol, karvarol kapsaisini, linalool, piperin ve timol antioksidan ve antimikrobiyel özellikler gibi faydalı özelliklere sahiptirler. $(6,7)$. Tibbi ve aromatik bitkilerden elde edilen bitkisel ekstraktlar antifungal (812), antibakteriyel, antiviral (9-13) antioksidan (9, 14-15), antitoksijenik $(13,16)$ ve performansi arttric1 ve sindirim sistemini uyarıcı (17) özellikleri ile ön plana çıkmaktadır. Sarımsak ve hardal gibi bitkisel ekstrakt ürünleri (allicin ve allyl-isothiocyanate) sindirim üzerinde pozitif etki göstermiştir. Bu pozitif etki tükürük salgısının, mide asidi salgısının ve sindirim enzimlerinin stimüle edilmesiyle ortaya çıkmaktadır (18).

Antimikrobiyel etkilere sahip olan sarımsak, kekik, tarçın, karanfil, biberiye gibi farklı bitki eksraktların patojen mikroorganizmaların (E.coli, Salmonella ve Clostridium) gelişimi durdurduğu performans değeri üzerindeki etkilerinin çok değişken olduğu ifade edilmektedir (19-21).

Araştırmaların 1şı̆̆ altında bitkilerin etken maddelerine göre antioksidan, antienflamatuvar, antiallerjen, antidepresif ve antimikrobiyel özelliklerinin olduğu, etken maddelerinin birlikte kullanımı durumunda sinerjik etki gösterebildiklerini ve sonuç olarak antibiyotiklere alternatif olabileceğini bildirmektir (7, 22-23). Bu çalışmada broyler rasyonlarına bitkisel ekstrakt karışımının (tarçın, kimyon, nane, sarımsak, anason, rezene) ilavesinin performans karkas parametreleri ve bazı iç organ ağılıkları üzerine etkilerinin belirlenmesi amaçlanmıştır.

\section{Gereç ve Yöntem}

Bu araştırma Kafkas Üniversitesi Hayvan Deneyleri Yerel Etik Kurulu (KAÜHADYEK/2019-044) raporunun iznine dayalı olarak yapılmıştır. Araştırma Kafkas Üniversitesi Veteriner Fakültesi Çiftliğine ait broyler ünitesinde yürütülmüştür. Çalışmada kullanılan etlik piliç civcivleri (Ross 308) Erzincan ilindeki özel bir kuluçkahaneden temin edilmiştir (Garanti Tavukçuluk-Erzincan). Araştırmada 192 adet 1 günlük civciv kullanılmıştır. Gruplarda 48 adet civciv olacak şekilde bir kontrol ve üç farklı düzeyde bitkisel ekstrakt ilaveli gruplar oluşturulmuştur. Her bir grup kendi içerisinde 12 civcivden oluşan 4 alt gruba ayrılmıştır. Her bir alt grup için eşit bölmelere $(1,40$ x 1,09) ayrılmıştır. Her bölmeye hayvanların ihtiyaçlarını karşılayacak düzeyde yemlik ve suluklar yerleştirilmiştir. Altlık malzemesi olarak 6 ila $8 \mathrm{~cm}$ derinliğinde odun talaşı kullanılmıştır. Deneme süresi 42 gün sürmüş olup civcivler haftalık tartılarak, kayıt altına alınmıştır. Hayvanlara grup yemlemesi uygulanmıştır. Civcivlere günlük tüketebilecekleri miktarda yem ve su ad libitum olarak sunulmuştur. Deneme öncesi kümeste gerekli temizlikler yapılmış ve dezenfeksiyon işlemi gerçekleştirilmiştir. Kümes radyatörlerle 1sıtılmış, gerekli hallerde elektrikli radyanlarla sıcaklığın ayarlanması sağlanmıştır. Kümes sıcaklığı ilk iki gün $33{ }^{\circ} \mathrm{C}( \pm 1)$ 'de tutulmuş, üçüncü günden itibaren kademeli olarak $24{ }^{\circ} \mathrm{C}$ 'ye kadar düşürülmüştür. Deneme süresince ölen havyanlar günlük olarak belirlenmiş ve kaydedilmiştir.

Denemede civcivler 0-21 günlük periyotta civciv yemi (\%24 HP, $3000 \mathrm{kcal} / \mathrm{kg} \mathrm{ME})$ ve 22-42 günlük periyotta ise bitirme yemi (\%20 HP, $3200 \mathrm{kcal} / \mathrm{kg}$ ME) ile beslenmiştir. Araştırmada kullanılan karma yemler ve yem besin madde bileşimi Tablo 1.'de sunulmuştur. Deneme için kullanılan bitkisel ekstrakt karışımı ticari özel bir firmadan tedarik edilmiştir (Biomin Ltd. Şti.-İstanbul). Ticari ürün (tarçın, kimyon, nane, sarımsak, anason, rezene) karışımından oluşmaktadır. Araştırmada kullanılan bitkisel ekstrakt karışımı deneme gruplarına sırasıyla; 0 (K), 1 gr $/ \mathrm{kg}(\mathrm{G} 1), 2$ gr $/ \mathrm{kg}$ (G2), 4 gr/kg (G3) gr/kg olacak şekilde karma yemlere ilave edilmiştir. 
Tablo 1: Temel Rasyonun Bileşimi (\%).

Table 1: Composition of the Basal Diet (\%).

\begin{tabular}{|c|c|c|}
\hline Ham Madde & Etlik Civciv Yemi & Etlik Piliç Yemi \\
\hline Misır & 43,00 & 54,15 \\
\hline Tam Yağlı Soya & 8,95 & 13,10 \\
\hline Soya Küspesi & 38,50 & 23,40 \\
\hline Et Kemik Unu & 3,00 & 2,70 \\
\hline Bitkisel Yağ & 2,80 & 3,00 \\
\hline Mermer Tozu & 1,50 & 1,50 \\
\hline DCP & 1,20 & 1,10 \\
\hline Tuz & 0,25 & 0,25 \\
\hline Vit-Min. Premiks* & 0,25 & 0,25 \\
\hline DL-Metiyonin & 0,20 & 0,20 \\
\hline L-Lizin & 0,15 & 0,15 \\
\hline L-Treonin & 0,20 & 0,20 \\
\hline Toplam & 100 & 100 \\
\hline
\end{tabular}

Hayvanlar denemenin başlangıcında tartılıp gruplara ayrılmış ve ilk tartımdaki gün ve saate uyularak 7., 14., 21., 28., 35 ve 42. günlerde gruplar halinde tartılarak haftalık ortalama canlı ağırlıklar tespit edilmiştir. Tartımlar arasındaki fark belirlenerek haftalık ortalama canlı ağırlık artışları (CAA) hesaplanmıştır. Denemede her bir alt gruba özel yem kovalarında yemler hazırlanmış ve bu yemler günlük olarak hayvanların tüketebileceği miktardan \%20 fazlasıyla yemliklere ilave edilmiş ve kayıt altına alınmıştır. Tüketilen yem miktarının hesaplanması için haftalık tartımlar sırasında bir önceki hafta hazırlanan yemlerden yem kovalarında ve yemliklerde kalan yemler çıkarılarak tüketilen toplam yem miktarı hesaplanmıştır. Bu miktar alt gruplar ve gruplar itibariyle mevcut hayvan ve gün sayısına bölünerek, grup ve alt gruplar bazında haftalık ortalama yem tüketimleri belirlenmiştir. Yemden yararlanma oranı ise iki tartım arasında tükettikleri toplam yem miktarının ortalama canlı ağırlık artışına bölünmesi ile hesaplanmıştır. Çalışma süresince gerçekleşen ölümler günlük olarak kayıt altında tutulmuştur.

Kesimin yapılacağı günden bir gün önce hayvanların önünden yemlikler alınarak hayvanlar aç bırakılmıştır. Kesim gününde her bir gruptan grup ortalamasını temsil edecek şekilde 10 adet etlik piliç kesim için ayrılmış ve kesim ağırlıkları belirlenerek işaretlenmiştir. Seçilen hayvanlar kesim hunilerine konularak kafaları ayrılmış ve kanın vücuttan tamamen boşalması sağlanmıştır. Haşlama kazanında bir süre bekletildikten sonra tüy yolma makinesi ile tüyleri uzaklaştırılmıştır. Tüy yolma işleminden sonra ayakları uzaklaştırılan hayvanların iç organlarının çıkarılması işlemi gerçekleştirilmiştir. Ortaya çıkan karkasların ağırlıkları belirlenmiş ve karkas randımanları hesaplanmıştır. Kesim işlemi sırasında her hayvana ait iç organlar (karaciğer, kalp, taşlık) hassas terazide tartılmış ve kaydedilmiştir.

\section{İstatistik analiz}

Canlı ağırlık artışı ve yem tüketimi, yemden yararlanma oranı ve kesim-karkas parametreleri için SPSS istatistik paket (SPSS 18.0) programında One Way Anova metodu kullanılmıştır. Gruplar arası önemlilik karşılaştırması için Duncan testi kullanılmıştır. 


\section{Bulgular}

Araştırmada kullanılan rasyonların besin madde miktarları ve metabolik enerji değerleri Tablo 2' de verilmiştir.

Tablo 2: Araştırmada kullanılan rasyonların besin madde miktarları (\%) ile metabolik enerji değerleri (kcal/kg).

Table 2: The amount of nutrients (\%) and metabolic energy values ( $\mathrm{kcal} / \mathrm{kg}$ ) of the rations used in the research.

\begin{tabular}{lcc}
\hline & $\begin{array}{l}\text { Etlik civciv yemi } \\
\text { (1-21. Günler) }\end{array}$ & $\begin{array}{c}\text { Piliç büyütme yemi } \\
(\mathbf{2 1 - 4 2 . ~ G u ̈ n l e r ) ~}\end{array}$ \\
\hline Metabolik Enerji* & 3024,50 & 3216,00 \\
Kuru Madde\% & 88,00 & 87,00 \\
Ham Protein \% & 24,56 & 20,00 \\
Ham Yağ \% & 3,56 & 4,59 \\
Ham Selüloz \% & 4,03 & 3,38 \\
Ca* & 1,27 & 1,19 \\
$\mathrm{P}^{*}$ & 0,70 & 0,60 \\
\hline
\end{tabular}

*Hesap yoluyla bulunmuştur.

Ölüm oranları Tablo 3' de verilmiştir. Deneme sonu itibarıyla kontrol grubunda 3, Grup 1 ve Grup 2' de 4, ve Grup 3 'te 2 adet ölüm gerçekleşmiştir. Gruplardaki ölüm oranları sırasıyla \%6,25; \%8,33; \%8,33 ve \%4,60 olarak hesaplanmıştır.

Tablo 3: Civcivlerin ölüm oranı.

Table 3: Mortality rate of the chicks.

\begin{tabular}{lccccccc}
\hline Gruplar & $7 .-14$. & $14 .-21$. & $21-28$. & $28 .-35$. & $35 .-42$. & $7 .-42$. & Ölüm Oranı (\%) \\
\hline K & 2 & 2 & - & - & 1 & 3 & 6,25 \\
G1 & - & 2 & - & 1 & 1 & 4 & 8,33 \\
G2 & 3 & - & 1 & - & 1 & 4 & 8,33 \\
G3 & - & 1 & - & - & - & 2 & 4,60 \\
\hline
\end{tabular}

Denemede haftalık canlı ağırlık ve yem tüketim tartımları sonucu elde edilen performans parametreleri Tablo 4‘de sunulmuştur. Tabloya göre günlük canlı ağılık artışı, toplam canlı ağırlık artışı, günlük yem tüketimi, toplam yem tüketimi ve yemden yararlanma oranları arasında bir farklılık olmadığı ortaya çıkmıştır $(\mathrm{P}>0,05)$. 
Tablo 4: Broyler performans değerleri, (Aritmetik Ort. \pm Std. Hata)

Table 4: Broiler performance values, (Mean \pm Std. Error of Mean).

\begin{tabular}{ccccccc}
\hline Gruplar & $\mathrm{N}$ & GCAA $(\mathrm{g})$ & $\mathrm{TCAA}(\mathrm{g})$ & $\mathrm{GYT}(\mathrm{g})$ & $\mathrm{TYT}(\mathrm{g})$ & $\mathrm{YYO}(\mathrm{g} / \mathrm{g})$ \\
\hline $\mathrm{K}$ & 45 & $67,78 \pm 1,59$ & $2846,77 \pm 66,94$ & $136,45 \pm 6,44$ & $5730,95 \pm 270,88$ & $2,08 \pm 0,13$ \\
$\mathrm{G} 1$ & 44 & $70,94 \pm 1,90$ & $2979,58 \pm 79,88$ & $145,73 \pm 2,83$ & $6120,70 \pm 118,95$ & $2,14 \pm 0,08$ \\
G2 & 44 & $70,19 \pm 1,97$ & $2948,22 \pm 83,00$ & $141,03 \pm 2,81$ & $5923,63 \pm 118,30$ & $2,08 \pm 0,09$ \\
G3 & 46 & $73,71 \pm 2,59$ & $3095,83 \pm 109,16$ & $142,21 \pm 5,33$ & $5973,00 \pm 224,21$ & $2,09 \pm 0,08$ \\
$\mathrm{P}$ & & 0,286 & 0,286 & 0,580 & 0,580 & 0,965 \\
\hline
\end{tabular}

GCAA: günlük canlı ağırlık artışı, TCAA: toplam canlı ağırlık artışı, GYT: günlük yem tüketimi, TYT: toplam yem tüketimi, YYO: yemden yararlanma orant.

Çalışma sonunda kesilen hayvanların kesim ve karkas parametreleri sonuçları Tablo 5.' de sunulmuştur. Kesim ağırlığı ile sıcak karkas ağırlığı ve oranları üzerine bitkisel ekstrakt karışımının etkisinin önemli olmadığı belirlenmiştir $(\mathrm{P}>0,05)$.

Tablo 5: Grupların ortalama karkas ağırlıkları (g) ve karkas randımanları (\%), (Aritmetik Ort. \pm Std. Hata)

Table 5: Average carcass weights (g) and carcass yields of the groups (\%), (Mean \pm Std. Error of Mean)

\begin{tabular}{ccccc}
\hline & N & Kesim A Ăırlı̆ $1(\mathrm{~g})$ & Karkas A Ăırlı̆̆ $(\mathrm{g})$ & Karkas Randımanı $(\%)$ \\
\hline K & 10 & $3029,20 \pm 64,94$ & $2399,40 \pm 50,50$ & $77,22 \pm 0,27$ \\
G1 & 10 & $2953,60 \pm 53,56$ & $2279,80 \pm 44,94$ & $77,16 \pm 0,24$ \\
G2 & 10 & $2936,70 \pm 40,03$ & $2245,50 \pm 23,45$ & $76,54 \pm 0,97$ \\
G3 & 10 & $2958,80 \pm 80,93$ & $2302,00 \pm 62,39$ & $77,82 \pm 0,48$ \\
P & & 0,149 & 0,159 & 0,122 \\
\hline
\end{tabular}

Kesim sonrası çıkarılan iç organların ağırlık ortalamaları Tablo 6' de sunulmuştur. Elde edilen sonuçlara göre kalp, karaciğer ve taşlık ağırlık ortalamalar arasında herhangi bir farklılık olmadığı tespit edilmiştir $(\mathrm{P}>0,05)$.

Tablo 6: Grupların ortalama bazı iç organ ağırlıkları, (Aritmetik Ort. \pm Std. Hata)

Table 6: Average internal organ weights (g) of the groups, (Mean \pm Std. Error of Mean)

\begin{tabular}{ccccc}
\hline Gruplar & N & Karaciğer & Kalp & Taşlik \\
\hline K & 10 & $54,50 \pm 1,70$ & $13,30 \pm 0,30$ & $26,90 \pm 1,55$ \\
G1 & 10 & $53,20 \pm 2,13$ & $13,60 \pm 0,85$ & $31,60 \pm 1,84$ \\
G2 & 10 & $52,00 \pm 2,21$ & $14,90 \pm 1,10$ & $32,20 \pm 1,56$ \\
G3 & 10 & $50,70 \pm 2,38$ & $14,20 \pm 0,87$ & $29,80 \pm 1,22$ \\
P & & 0,191 & 0,474 & 0,895 \\
\hline
\end{tabular}




\section{Tartışma ve Sonuç}

Yaptı̆̆ımız bu çalışmada broyler karma yemlerine ilave edilen farklı düzeylerde bitkisel ekstrakt karışımlarının (tarçın, kimyon, nane, sarımsak, anason, rezene) performans parametreleri üzerine olan etkileri incelendiğinde; kontrol, 1. grup $(1 \mathrm{~g} / \mathrm{kg}), 2$. grup $(2 \mathrm{~g} / \mathrm{kg})$ ve 3.gruba $(4 \mathrm{~g} / \mathrm{kg})$ ait canlı ağırlık ve canlı ağırlık artışı açısından farklılık oluşmamıştır. Çalışmaların birçoğunda bitkisel ekstrakt olarak büyüme performansı ve diğer parametreler üzerine farklı sonuçlar verdiği görülmüştür. Bu araştırmaya benzer şekilde yapılan çalışmalarda uygun çevresel şartlarda ve yemlerle beslenen hayvanlarda bitkisel ekstrakt ilavesinin etkili olmadığı bildirilmektedir $(5,14,24)$. Yine broyler karma yemlerine bitkisel ekstrakt karışımları ilavesinin büyüme performansı üzerine etkisinin olmadığını ifade eden uyumlu çalışmalar bulunmaktadır (25-28). Bu araştırıcılar çevre koşulları iyileşmesi ve patojen yükünün azalmasıyla bitkisel ekstraktlardan beklenen etkinin azaldığını rapor etmişlerdir.

Al-kasie (29) broylerler rasyonlarına kekik ve tarçın ekstraktının, Mohammed ve Abbas (30) ise rezene ilavesinin performans değerlerini artırdığını ifade etmiştir. Jamroz ve ark (21) bitkisel ekstrakt karışımının (karvakrol, sinemaldehit) broylerlerde canlı ağırlık parametrelerini artırdığını ve bu artışın, tarçının ana etken maddesi olan sinemaldehitin pankreas ve bağırsak enzimi salgısını artırarak besinlerin emilimini artırmasından kaynaklandığı ifade edilmektedir. Aynı şekilde çalışmamızla uyum göstermeyen kanatlı rasyonlarında farklı bitkisel ekstraktların canlı ağırlığı artırdığı yönünde çalışmalar da bulunmaktadır (31-38). Settle ve ark (39) broyler rasyonlarına fitojenik yem katkısı, Kumar ve Berwal (40) sarımsak yağı, Lewis ve ark (41) sarımsak tozu kullanımının broylerlerde büyüme performansını arttırdığını rapor etmiştir. Bitkisel ekstrakt katkısının broylerlerde performansı olumsuz yönde etkilediğini bildiren çalışmalar mevcuttur (42-43). Mountzouris ve ark (44) broylerlerde büyüme performansı üzerine bitkisel eksraktların etkinliğinin yemde bulunma düzeyi ve hayvanın büyüme dönemi ile ilgili olduğunu bildirmiştir. Broylerlerde bitkisel ekstraktların performansa etki mekanizmaları henüz tam olarak bilinmemekle beraber, bunun besin madde bileşenlerinin stabilizasyonu, bağırsak mikroflorası, mikroorganizma konsantrasyonu ile pankreas ve sindirim kanalı enzimlerinin aktive olmasıyla sağlandığı düşünülmektedir.

Tüm deneme süresince deneme gruplarında yem tüketim değerleri kontrol grubuna göre rakamsal olarak daha yüksek olduğu fakat gruplar arasındaki bu farkın önemli olmadığı görülmüştür. Deneme süresince yemden yararlanma oranı gruplar arasında fark oluşturmamıştır (Tablo 4). Fascina ve ark. (28) bitkisel ekstrakt karışımlarının, Nobakht ve Mehmannavaz (45), broylerlerde farklı yağ kaynaklarının, Khaksar ve ark. (38) bıldırcınlarda timol esansiyel yağının yem tüketimi ve yemden yararlanma oranını etkilemediğini bildirmiştir. Bu bulgular, bitkisel ekstraktları konu alan ve etlik piliçlerde yem tüketiminin ve yemden yararlanma oranının etkilenmediğini bildiren Hernandez ve ark. (25), Zhang ve ark. (24), Muhl ve Liebert (46), Ocak ve ark. (27), Lee ve ark. (47), Mathlouthive ark. (48), Küçükyılmaz ve ark. (49)' nın çalışmaları ile uyumludur. Bitkisel ekstraktların organizmada çeşitli bulgulara sebep olmasının nedeni, yapısında bulunan aktif moleküllerden kaynaklanmaktadır. Mevcut çalışmada, Lee ve ark.(26) ile Günal ve ark' ın (50) bitkisel ekstraktların broylerlerde yem tüketimini etkilemediği bulgularıyla benzerlik gösterirken Tekeli ve ark'nın (51) broylerlerde bitkisel ekstraktların yem tüketimini artırdığı; Halle ve ark'nın (52), broyler yemlerine kekik ve kekik esansiyel yağı ilavesinin günlük yem tüketimini azalttığı, yemden yararlanmayı önemli düzeyde iyileştirdiği, Jamroz ve ark.'nın (21) kekik, tarçın ve karabiber karışımından oluşan bitkisel ekstraktın broylerlerde yemden yararlanma oranını \% 4 civarında arttığı sonuçlarıyla çelişmektedir. Deneme sonuçları, broylerlerde $(29,43,48,53-54)$ yapılan çalışma sonuçlarıyla da uyum göstermemektedir. Nitekim bitkisel ekstraktlarla beslenen hayvanlarda farklı yaşlarda ve evrelerde yemden yararlanma oranı bakımından değişimler görülmektedir. Araştırıcıların bildirdiklerine göre rasyonlarında farklı düzeyde bitkisel ekstrakt bulunan hayvanlarda 14 günlük yaşta (55), 14-21 ve 28-35 günlük yaşlarda (25), 29-42 günlük yaşta (44) yemden yararlanma oranlarının iyileştiği yönünde bulgular bulunmaktadır. Yemden yararlanma oranlarını üzerine bitkisel ekstraktların olumlu etki göstermesi enzim aktivitesinin artması ve daha fazla besin maddesinin emiliminden kaynaklanabilir.

Gruplarına ait karkas verim parametreleri Tablo 5' de verilmiştir. Deneme sonunda gruplar arasında bu parametreler açısından istatistiksel bir farklılık şekillenmemiştir ( $\mathrm{P}>0,05)$. Mevcut çalışma bulguları Muhl ve Liebert (46)' in fitojenik ekstraktların broylerlerde karkas verimini etkilemediği, Halle ve ark.' in (52), broyler yemlerine kekik veya kekik yă̆ı ilavesinin; Hernandez ve ark.'ın (25) oregano, tarçın ve biber karışımının, Bozkurt ve ark'ın (56) 
broyler rasyonlarına şerbetçiotu ekstraktı ve oregano yağı ilavesinin, Şimsek ve ark'1n (57) kekik karanfil ve anason karışımlarının broylerlerde karkas verim ve özeliklerini etkilemediği bildirişi ile de uyumludur. Bu çalışmalar arasındaki uyum yetiştirme koşullarının benzerliğinden kaynaklanmış olabileceği düşünülmektedir.

Karkas verimleri açısından elde edilen sonuçlar bazı araştırmalarla farklılık göstermektedir. Fascina ve ark. (28) fitojenik ekstraktların karkas verimini, Al-Kasie ve ark. (29) kekik ve tarçın ilavesinin karkas randımanını önemli bir şekilde artırdığını bildirmiştir. Bunların yanında bitkisel ekstraktların kesim karkas özellikleri üzerine önemli artış sağladığını ve bu etkinin ekstraktların iştah açıcı, enzim salgılatıcı ve antimikrobiyel etkilerinden kaynaklandığını bildiren çalışmalar mevcuttur $(49,54)$.

Araştırma sonunda değerlendirilen kalp, karaciğer ve taşlık ağırlıkları arasında bir farklılık görülmemiştir (P>0,05). Lee ve ark. (42) denemenin sonunda karaciğer ağırlıklarının istatistiksel olarak önemsiz olduğu belirtilmiştir. Mansoub' un (58) broyler rasyonlarına oregano ilavesinin taşlık ağırlı̆̆ını, Şimşek ve ark.'ın (57) esansiyel yağ karışımının broylerlerde kalp ve karaciğer ağılığını, Khaksar ve ark. (38)' in bıldırcınlarda kekik esansiyel yağının karaciğer ve kalp ağırlıklarını, Çelik ve Şahin (59)' in broylerlerde içme sularına katılan nane, kekik, ardıç ve biberiye karışımının kalp, karaciğer ve taşlık ağırlıklarını etkilemediği bulgularıyla benzerlik arz etmektedir. Araştırma sonuçlarımız, broylerlerde esans yağ karışımı kullanılarak yapılan araştırmalardan; Hernandez ve ark.' ’n (25) taşlık ve karaciğer ağırlıkları; Küçükyılmaz ve ark.'ın (49) karaciğer ağırlıkları; Köksal ve Küçükersan'ın (60) iç organ ağırlıklarına etkisi bildirişleriyle de benzerlik göstermektedir.

Mansoup (58) broyler yemlerine ilave edilen oregano yağının karaciğer ağırlığını; Toyghani ve ark. (54) kekik tozu ilavesinin kalp ve taşlık ağırlığını; Al-kasie (29) kekik ve biberiye aromatik bitkilerinden elde edilen iki farklı ekstrakt katkısının kalp, karaciğer ve taşlık ağırlıklarını arttırdığını bildirmektedir.

Sonuç olarak; broyler rasyonlarına farklı düzeylerde $(0,1 \mathrm{~g} / \mathrm{kg}, 2 \mathrm{~g} / \mathrm{kg}, 4 \mathrm{~g} / \mathrm{kg})$ ilave edilen bitkisel ekstrakt karışımlarının (tarçın, kimyon, nane, sarımsak, anason, rezene) performans, karkas ağırlıkları ve randımanları ile bazı iç organ (kalp, karaciğer, taşlık) ağırlıkları üzerine etkisi bulunamamıştır. Bu durumun hayvanların sağlıklı şartlarda yetiştiği, stres durumlarına maruz kalmadığı ve kullanılan rasyonun bileşiminin sonucu olarak rol oynadığ 1 düşünülmektedir. $\mathrm{Bu}$ araştırma sonuçları ile diğer bildirişler arasında farklılıkların bulunması kullanılan ekstrakt maddelerin ve bitkilerin biyoaktif özelliklerine bağlı olarak değiştiği, hayvanların farklı yaş, tür ve çevrede olması, kullanılan etken maddenin doz ve uygulama şartları coğrafik bölge ve bitkisel kaynakları orijini gibi sebeplerinde rol oynadığı kanaatine varılmıştır.

\section{Kaynaklar}

1. Dibner JJ, Richards JD (2005): Antibiotic growth promoters in agriculture: history and mode of action. Poult Sci, 84, 634-643.

2. Nasir Z, Grashorn MA (2006): Use of Black cumin (Nigella sativa Linn.) as alternative to antibiotics in poultry diets. 9 Tagung. Schweine und Geflugelernahrung, Martin Luther Universitat Halle Wittenberg, Halle, Germany, 28-30 November, 210-213.

3. Brenes A, Roura E (2010): Essential oils in poultry nutrition: Main effects and modes of action. Anim Feed Sci and Tech, 158, 1-14.

4. Windisch WM, Schedle K, Plitzner C, Kroismayr A (2008): Use of phytogenic products as feed additives for swine and poultry. J Anim Sci, 86 (14 Suppl.), E140-E148.

5. Lee KW, Evert H, Beynen AC (2004): Essential Oils in Broiler Nutrition. Int J Poult Sci, 3; 738-752.

6. Ruberto G, Barrata M, Sari M, Kaabehe M (2002): Chemical composition and antioxidant activity of essential oils from Algerian Origanum glandulosum Desf. Flavour and Fragrance J, 17, 251-254.

7. Krishan G, Narang A (2014): Use of essential oils in poultry nutrition: A New Approach. J Adv Vet and Anim Res, 1, 156-16.

8. Hammer KA, Carson CF, Riley TV (1999): Antimicrobial activity of essential oils and other plant extracts. J Appl Microbiol, 86, 985. 
9. Svoboda PK., Hampson BJ (1999): Bioactivity of essential oils of selected temperate aromatic plants: antibacterial, antioxidant, antiinflammatory and other related pharmacological activities. Aromatopia 35, 50-54.

10. Dorman HJD, Deans SG (2000): Antimicrobial agents from plants: Antibacterial Activity of Plant Volatile Oils. J Appli Microbiol, 88; 308316.

11. Rauha JP, Remes S, Heinonen M, Hopia A, Kähkönen M, Kujala T, Pihlaja K, Vuorela H. Ve Vuorela $P$ (2000): Antimicrobial effects of Finnish plants extracts containing flavonoids and other phenolic compounds. Int J Food Microbial. 56, 3-12.

12. Lambert RJW, Skandamis PN, Coote PJ ve Nychas GJ (2001): A study of the minimum inhibitory concentration and mode of action of oregano essential oil, thymol and carvacrol. J Appli Microbiol 91(3), 453462.

13. Ultee A, Smid EJ (2001): Influence of Carvacrol on Growth and Toxin Production by Bacillus cereus. Int J Food Microbiol. 64, 373-378.

14. Botsoglou NA, Florou-Paner P, Christaki E, Fletouris DJ and Spais AB (2002): Effect of dietary oregano essential oil on performance of chickens and on iron-induced lipid oxidation of breast, thigh and abdominal fat tissues. Bri Poult Sci 43, 223- 230.

15. Botsoglou NA, Christaki E, Florou-Paneri P, Giannenas I, Papageorgiou G, Spais AB (2004): The effect of a mixture of herbal essential oils or $\alpha$-tocoheryl acetate on performance parameters and oxidation of body lipid in broylers. S Afr J Anim Sci, 34, 52-61.

16. Juglal S, Govinden R, Odhav B (2002): Spice oils for the control of co-occurring mycotoxin producing fungi. J Food Pro, 65, 683-687.

17. Baser KH (2008): Biological and pharmacological activities of carvacrol and carvacrol bearing essential oils. Curr Pharm Des, 14, 3106.

18. Langhout P (2000): New additives for broiler chickens. World Poult -Elsevier, 16(3), 22-27.

19. Ross ZM, O'Gara EA, Hill DJ, Sleightholme HV, Maslin DJ (2001): Antimicrobial properties of garlic oil against human entericbacteria evaluation of methodologie sand comparisons with garlic oil sulphides and garlic powder. Appl Environ Microbiol, 67, 475-480.

20. Griggs JP and JP Jacob (2005): Alternatives to antibiotics for organic poultry production. J Appli Poult Res 14, 750-756.

21. Jamroz D, Wiliczkiewicz A, Wertelecki T, Orda J, Scorupinska J (2005): Use of active substances of plant origin in chicken diets based on maize and domestic grains. Bri Poult Sci, 46, 485-493.

22. Wei A, Shibamoto T (2007): Antioxidant activities and volatile constituents of various essential oils. J Agri Food Chem, 55, 1737-1742.

23. Yitbarek MB (2015): Phytogenics as feed additives in poultry production: A review. Int J Ext Res, 3, 49-60.

24. Zhang KY, Yan F, Keen CA, Waldroup PW (2005): Evaluation of microencapslated essential oils and organic acids in diets for broiler chickens. Int J Poult Sci, 4 (9), 612-619.

25. Hernandez F, Madrid J, Garcia V, Orengo J, Megias MD (2004): Influence of two plant extracts on broiler performance, digestibility, and digestive organ size. Poult Sci, 85, 1466-1471.

26. Lee KW, Everts H, Kappert HJ, van der Kuilen J, Lemmers AG, Frehner M, Beynen AC (2003): Growth performance, intestinal viscosity, fat digestibility and plasma cholesterol in broiler chickens fed a rye-containing diet without or with essential oil components. Int J Poult Sci, 3, 613-618.

27. Ocak N, Erener G, Ak FB, Sungu M, Altop A, Ozmen A (2008): Performance of broilers fed diets Thymus vulgaris L supplemented with dry peppermint (Mentha piperita L.) or thyme leaves as growth promoter source. Czech J Anim Sci, 53, 169-175.

28. Fascina VB, Sartori JR, Gonzales E, Barros de Carvalho F, Pereira de Souza IMG, Polycarpo GV, Stradiotti AC, Pelicia V (2012): Phytogenic additives and organic acids in broiler chicken diets. R Bras Zootec, 41, 2189-2197.

29. Al-Kassie (2009): GAM. Influence of two plant extracts derived from thyme and cinnamon on broiler performance. Pakistan Vet J, 29, 169- 173.

30. Mohammed AA, Abbas RJ (2009): The effect of using fennel seeds (Foeniculum vulgare L.) on productive performance of broiler chickens. InT J Poult Sci, 8, 642-644. 
31. Fukayama EH, Bertechini AG, Geraldo A, Kato RK, Murgas LDS (2005): Extrato de orégano como aditivo em rações para frangos de corte. $\mathrm{R}$ Bras Zootec, 34, 2316-2326.

32. Lippens M, Huyghebaert G, Cerchiari E (2005): Effect of the use of coated plant extracts and organic acids as alternatives for antimicrobial growth promoters on the performance of broiler chickens. ARCH, 69, 261-266.

33. Cross DE, McDevitt RM, Hillman K, Acamovic T (2007): The effect of herbs and their associated essential oils on performance, dietary digestibility and gut microflora in chickens 7 to 28 d of age. Bri Poult Sci, 48, 496506.

34. Spernakova D, Mate D, Rozanska H, Kovac G (2007): Effect of dietary rosemary extract and $\alpha$ tocopherol on the performance of chickens, meat quality, and lipid oxidation in meat storage under chilling conditions. B Vet I Pulawy, 51, 585-589.

35. Rizzo PV, Menten JFM, Racanicci AMC, Traldi, AB, Silva CS, Pereira PWZ (2010): Extratos vegetais em dietas para frangos de corte. R Bras Zootec, 39, 801-807. (Portuguese with English abstract)

36. Tiihonen K, Kettunen H, Bento MHL, Saarinen M, Lathinen S, Ouwehand AC, Schulze H, Rautonen N (2010): The effect of feeding essential oils on broiler performance and gut microbiota. Bri Poult Sci, 51, 381-392.

37. Kumar S, Sharadamma KC, Radhakrishna PM (2010): Effects of a garlic active based growth promoter on growth performance and specific pathogenic intestinal microbial counts of broiler chicks. Int J Poult Sci, 9, 244246.

38. Khaksar V, van Krimpen M, Hashemipour H, Pilevar M (2012): Effects of thyme essential oil on performance, some blood parameters and lleal microflora of japanese quail. Japan Poult Sci Assoc, 49: 106-110.

39. Settle T, Leonard SS, Falkenstein E, Fix N, Van Dyke K, Klandorf H (2014): Effects of a phytogenic feed additive versus an antibiotic feed additive on oxidative stress in broiler chicks and a possible mechanism determined by electron spin resonance. Int J Poult Sci, 13(2), 62-69.

40. Kumar M, Berwal JS (1998): Sensitivity of food pathogens to garlic (Allium sativum). J Appli Microbiol, 84, 213-215.

41. Lewis MR, Rose SP, Mackenzie AM, Tucker LA (2003): Effects of dietary inclusion of plant extracts on the growth performance of male broiler chickens. Bri Poult Sci, 44 (1), 43-44.

42. Lee KW, Everts H, Kappert HJ, Yeom KH, Beynen AC (2003): Dietary carvacrol lowers body weight gain but improves feed conversion in female broiler chickens. J Appli Poult Res, 12, 394-399.

43. Puvaca N, Stanacev V, Glamocic D, Levic J, Peric L, Stanacev ve Milic D (2013): Beneficial effects of phytoadditives in broiler nutrition. World's Poult Sci J, 69, 2734.

44. Mountzouris KC, Paraskevas V, Tsirtsikos P, Palamidi I, Steiner T, Schatzmayr G, Fegeros K (2011): Assessment of a phytogenic feed additive effect on broiler growth performance, nutrient digestibility and caecal microflora composition. Anim Feed Sci and Tech, 168, 223-231.

45. Nobakht A ve Mehmannavaz Y (2012): Effects of saturated and unsaturated fats in starter and grower feeds on performance and carcass traits of broilers. J Basic Appl Sci Res, 2(2), 967-970.

46. Muhl A, Liebert F (2007): Growth, nutrient utilization and threonine requirement of growing chicken fed threonine limiting diets with commercial blends of phytogenic feed additives. J Poult Sci, 44, 297-304.

47. Lee KW, Everts H, Kappert HJ, Frehner M, Losa R, Beynen AC (2010): Effects of dietary essentialoil components on growth performance, digestive enzymes and lipid metabolism in female broiler chickens. Bri Poult Sci, 44, 450-457.

48. Mathlouthi N, Bouzaienne T, Oueslati I, Recoquillay F, Hamdi M, Urdaci M, Bergaoui R (2011): Use of rosemary, oregano, and a commercial blend of essential oils in broiler chickens: In vitro antimicro- bial activities and effects on growth performance. J Anim Sci, 90, 813-823.

49. Küçükyılmaz K, Çatlı AU, Çınar M (2012): Etlik piliç yemlerine esansiyel yă̆ karışımı ilavesinin büyüme performansı, karkas randımanı ve bazı iç organ ağırlıkları üzerine etkileri. Kafkas Univ Vet Fak Derg, 18 (2), 291-296.

50. Günal M, Yaylı G, Kaya N, Karahan N and Sulak O (2006): The effects of antibiotic growht promoter, probiotic or organic acid supplementation on performance, intestinal microflora and tissue of broilers. Int $\mathrm{J}$ Poult Sci, 5 (2),149-155. 
51. Tekeli A, Çelik L, Kutlu,HR, and Görgülü M (2006): Effect of Syzygium aromaticum and Zingeber officinale essential oils on performance and some carcass, blood and intestinal parameters of broilers. European Assoc Anim Prod, Antalya.

52. Halle I, Thomann R, Bauermann U, Henning M, Kohler P (2004): effects of a graded supplementation of herbs and essential oils in broiler feed on growth and carcass traits. Landbauforschung Volkenrode, 54, 219-229.

53. Çelik E, Çelik GY (2007): Bitki uçucu yağlarının antimikrobiyal özellikleri. Orlab On-Line Mikro Derg, 5(2), $1-6$.

54. Toghyani M, Tohidi M, Gheisari AA, Tabeidian SA (2010): Performance, immunity, serum biochemical and hematological parameters in broiler chicks fed dietary thyme as alternative for an antibiotic growth promoter. African J Biotech, 9, 6819-6825.

55. Giannenas I, Florou-Paneri P, Papazahariadou M, Christaki E, Botsoglou NA, Spais AB (2003): Effect of dietary supplementation with oregano essential oil on performance of broilers after experimental infection with Eimeria tenella, Arch Tierernahr 57, 99-106.

56. Bozkurt M, Çatlı AU, Küçükyılmaz K, Çınar M, Bintaş E (2007): Etlik piliç yemlerinde organik asit ve esansiyel yağ karışımı ile kombinasyonlarının ilave edilmesinin besi performansı üzerine etkisi. 4 . Ulusal Hayvan Besleme Kongresi, Bursa, Türkiye, 24-28 Haziran.

57. Şimşek ÜG, Güler T, Çiftçi M, Ertaş ON, Dalkılıç B (2005): Esans yağ karışımının (kekik, karanfil ve anason) broylerlerde canlı ă̆ırlık, karkas ve etlerin duyusal özellikleri üzerine etkisi. YYÜ Vet Fak Derg, 16 (2), 1-5.

58. Mansoub NH (2011): Performance, carcass quality, blood parameters and Immune System of broilers fed diets supplemented with oregano oil (Origanum sp.). Annals of Bio Res, 2: 652-656.

59. Çelik R, Şahin T (2015): İ̧̧me suyuna farklı düzeylerde ilave edilen esansiyel yă̆ karışımlarının (nane+ kekik+ardıç+ biberiye) broylerlerde besi performansı, kesim ve karkas özellikleri üzerine etkisi. Vet Hek Der Derg, 86 (1), 22-35.

60. Köksal BH, Küçükersan MK (2012): Broyler rasyonlarına humat ile bitki ekstraktı karışımı ilavesinin büyüme performansı, Bazı bă̆ışıllık ve serum biyokimya değerlerine etkileri. Kafkas Üniv Vet Fak Derg, 18(1), 103-108. 